\title{
Hypertonic saline versus normal saline nebulization in hospitalized children with acute bronchiolitis.
}

\footnotetext{
1. MBBS

Postgraduate Registrar Pediatric Medicine,

The Children's Hospital \& $\mathrm{ICH}$, Multan

2. MBBS, FCPS (Pediatric Medicine) Assistant Professor Paediatric Medicine

The Children's Hospital \& $\mathrm{ICH}$, Multan.

3. MBBS, FCPS (Paediatric Medicine) Associate Professor Paediatric Medicine

The Children's Hospital \& ICH, Multan.
}

Correspondence Address:

Dr. Asim Khurshid

Department of Paediatric Medicine

The Children's Hospital \& ICH, Multan.

asimkhurshiddr@gmail.com

Article received on:

24/03/2020

Accepted for publication:

27/05/2020

\begin{abstract}
Maleeha Saleem ${ }^{1}$, Maria Saleem ${ }^{2}$, Asim Khurshid ${ }^{3}$
ABSTRACT... Objectives: To compare mean length of hospital stay (LOHS) after treatment with nebulized hypertonic saline (HS) versus normal saline (NS) in hospitalized children with acute bronchiolitis (AB). Study Design: Randomized Control Trial. Setting: Department of Pediatric Medicine, The Children's Hospital and Institute of the Child Health, Multan. Period: July 2018 to January 2019. Material \& Methods: A total of 206 hospitalized children having AB were enrolled. Group A ( $n=103)$ was nebulized with $2 \mathrm{ml}$ of $3 \%$ HS while group B $(n=103)$ was nebulized with $2 \mathrm{ml}$ of $0.9 \%$ saline solution. Clinical severity score was calculated daily to monitor progress of patients. Patients were discharged from hospital with clinical severity score of 4 or less and length of hospital stay was noted. Results: Overall, mean age was $5.83 \pm 4.48$ months. Among 206 patients 139 (67.5\%) were males and 67 (32.5\%) females. Mean duration of disease was noted to be $3.57+2.2$ days. In Group-A, mean LOHS was $36.29+18.4$ hours in comparison to $39.15+16.1$ hours in Group B ( $p$-value $=0.2365$ ). Conclusion: Nebulized HS $3 \%$ and NS $0.9 \%$ were not found to have any significant advantage over each other in terms of LOHS among hospitalized children having acute bronchiolitis.
\end{abstract}

Key words: $\quad$ Acute Bronchiolitis, Hypertonic Saline, Length of Hospital Stay, Normal Saline.

Article Citation: Saleem M, Saleem M, Khurshid A. Hypertonic saline versus normal saline nebulization in hospitalized children with acute bronchiolitis. Professional Med J 2020; 27(12):2734-2738.

https://doi.org/10.29309/TPMJ/2020.27.12.4667

\section{INTRODUCTION}

Respiratory infections are considered a serious set of diseases responsible for major proportion of mortality among children aged below 5 years. ${ }^{1}$ Bronchiolitis is a frequent issue among children aged below 2 years and characterized as tachypnea, increased breathing after upper respiratory prodrome, nasal congestion as well as rhinorrhea and increased respiratory efforts. ${ }^{2}$ Acute bronchiolitis (AB) is described as inflammation of the bronchioles following an acute viral infection $(\mathrm{AVI}){ }^{3}$ Among infants, $A B$ is the most common type of lower respiratory tract infection (LRTI). Course of bronchiolitis is self limiting among most children but some of them could also go on to have worst outcomes. ${ }^{4}$ Annual cost on hospitalized children for bronchiolitis surges around $\$ 500$ million in the United States. ${ }^{5}$

Respiratory syncytial virus (RSV) is known to be the most common organism responsible for
AB. ${ }^{6}$ RSV causes about 60 to $80 \%$ of bronchiolitis cases among infants and young children. ${ }^{7,8}$ Metapneumovirus, parainfluenza virus, adenovirus and mycoplasma pneumoniae are some of the other most common organisms seen to have involved in $\mathrm{AB} .^{9}$

Use of bronchodilators, epinephrine, glucocorticoids as well as chest physiotherapy are some of the most frequent options adopted to treat $A B$ but all have shown inconclusive or inappropriate results favoring good outcomes. ${ }^{10}$ Supportive care like oxygen exchange along with maintenance of hydration are known to be the mainstay of bronchiolitis treatment. ${ }^{11}$ Some researchers have evaluated the effectiveness of nebulized hypertonic saline $3 \%$ in $A B$ and suggested that it might be influential in the course of disease and might reduce the length of hospital stay (LOHS). ${ }^{12}$ Although variability exists but no significant effect of diagnostic tests, 
types of treatment adopted in the emergency departments (EDs) or criteria for admissions have on the clinical outcome of $A B$ among children. ${ }^{13}$

Not much literature exist comparing HS versus NS among hospitalized children with $A B$ and to the best of our knowledge, there is lack of local data as well, so this study was planned to compare mean LOHS after treatment with nebulized hypertonic saline (HS) versus normal saline (NS) in hospitalized children with $A B$.

\section{MATERIAL \& METHODS}

This randomized control trial was conducted at The Department of Pediatric Medicine, The children's Hospital and The Institute of Child Health, Multan, from July 2019 to January 2020. Approval from the institutional Ethical committee was seeked and informed consent was sought from the parents or guardians of all the study participants.

A total of 206 children (103 in each group), aged 2-24 months of either sex, having $A B$ and onset of disease within last 5 days were enrolled. $A B$ clinical severity scoring was done adopting Wang Score ${ }^{14}$ and children having score of 6 or more enrolled. Children having underlying bronchopulmonary dysplasia, chronic lung diseases (On history and medical records), neuromuscular abnormalities, immunodeficiency or congenital heart disease (on history and medical records), syndromic babies with dysmorphic clinical features or whose parents did not give consent of participation, were excluded.

In all hospitalized children, at the time of inclusion in study, baseline information like age, gender, vital signs (heart rate, respiratory rate, and temperature), disease duration along with clinical severity score were recorded. Study participants were randomly assigned to two groups (Group-A and Group-B, 103 children in each group) by sealed envelopes. Children in Group A were nebulized using $2 \mathrm{ml}$ of $3 \% \mathrm{HS}$ while in Group-B, $2 \mathrm{ml}$ of $0.9 \%$ saline solution was used. Each children was nebulized every 4 hours during treatment. These patients were closely monitored and clinical severity score was calculated daily to monitor progress of patients and to determine outcome in both cases. Patients were discharged from hospital which their clinical severity scores as 4 or less. All the study findings were recorded on a predesigned proforma.

Data was entered in SPSS version 20.0. Mean and standard deviation were calculated for quantitative variables like age and duration of illness while frequencies and percentages were noted for qualitative variables like gender and use of antibiotics. Chi square test was applied to compare baseline characteristics of qualitative variables while independent sample t test was used for quantitative variables in between both groups. Paired sample $t$ test was applied to compare the hospital stay between both groups. $P$ value $<0.05$ was considered as significant.

\section{RESULTS}

Overall, mean age was $5.83 \pm 4.48$ months. Among 206 patients 139 (67.5\%) were males and 67 (32.5\%) females. Mean weight was $5.29+1.84$ $\mathrm{kg}$ while duration of disease was noted to be $3.57+2.2$ days. Table-I highlights the baseline characteristics of patients of both groups. No statistical difference was found in between both groups in terms of baseline characteristics ( $p$-value $>0.05$ ).

Overall, mean LOHS was noted to be $37.24+18.2$ hours. In Group-A, mean LOHS was 36.29+18.4 hours in comparison to $39.15+16.1$ hours in Group B but there was no statistical difference noted in between both the groups ( $p$-value = 0.2365). No adverse events related to studied drugs were reported by any of the parents or caregivers. Table-II

\section{DISCUSSION}

$A B$ is known to be a contagious disease involving infants and commonly caused by viruses. Current treatment of $A B$ comprises of different options like bronchodilators, corticosteroids, and antiviral medications but there is no consensus about the effectiveness of a standard set of drugs. 


\begin{tabular}{|l|l|c|c|c|}
\hline \multicolumn{2}{|c|}{ Baseline Characteristics } & Group-A (n=103) & Group-B (n=103) & P-Value \\
\hline Gender & Male & $74(70.9 \%)$ & $65(63.1 \%)$ & 0.1807 \\
\hline Female & $29(29.1 \%)$ & $38(36.9 \%)$ & 0.8019 \\
\hline Age in Months (Mean+SD) & $5.78+4.32$ & $5.94+4.81$ & 0.5697 \\
\hline Weight in Kg (Mean+SD) & $5.24+1.92$ & $5.39+1.86$ & 0.3684 \\
\hline Duration of disease in Days (Mean+SD) & $3.42+2.1$ & $3.71+2.5$ & \\
\hline
\end{tabular}

Table-I. Baseline characteristics of study participants

\begin{tabular}{|l|c|c|c|}
\hline & Group-A & Group-B & P-Value \\
\hline Length of Hospital Stay in Hours (Mean+SD) & $36.29+18.4$ & $39.15+16.1$ & 0.2365 \\
\hline
\end{tabular}

Table-II. Length of hospital stay (hours) in between both groups

We noted that overall mean age was $5.83 \pm 4.48$ months. Findings of a recent previous local study done by Salman MK et $\mathrm{al}^{12}$ noted that $71.1 \%$ of the infants in NS group and $78.9 \%$ of the infants in HS groups treated with $A B$ were aged less than 6 months. Many other researchers have also found $A B$ to be most prevalent in the $1^{\text {st }} 6$ months of life. ${ }^{15-17}$ In the present study, $67.5 \%$ of the study participants with $A B$ were male. Male predominance has been an obvious finding in the previous studies among infants with $A B$. Most authors reported male prevalence to be between $60-72 \%$ in $A B .{ }^{15,16,18}$

In the present study, although in children nebulized with HS had shorter LOHS (36.29+18.4 hours) compared to those nebulized with NS $(39.15+16.1$ hours) but the difference was not of statistical significance. Sarrell EM et al ${ }^{19}$ are considered the first researchers to conduct a research on nebulized 3\% HS among children having viral bronchiolitis and found it to minimize the related symptoms. Zhang $\mathrm{L}$ et $\mathrm{al}^{20}$, in their meta-analysis of four randomized trials concluded that $3 \% \mathrm{HS}(2 \mathrm{ml}$ in one study and $4 \mathrm{ml}$ in other three studies) reduced the LOS along with rapid betterment in severity scores among infants with $\mathrm{AB}$.

The results of our study in terms of LOHS among both treatment groups are aligned with those of Chen $\mathrm{YJ}$ et $\mathrm{al}^{21}$ who, in a meta-analysis, noted no significant difference in terms of LOS between HS and NS groups. A study from Iran by Reisi $\mathrm{M} \mathrm{et}^{22}$ al also supported the results of our findings that there was no significant difference in between
HS $3 \%$ and NS $0.9 \%$ in terms of LOHS among children having $\mathrm{AB}$.

Florin TA et $\mathrm{al}^{23}$ in randomized clinical trial found NS to be more efficacious than HS among patients presenting with $A B$ in the emergency department. Florin TA et $\mathrm{al}^{23}$ also endorsed that HS should not be adopted at acute care facilities. Sharma BS et $\mathrm{al}^{24}$ from India found no difference of LOHS or CSS among children having $\mathrm{AB}$ treated with nebulized HS $3 \%$ or NS $0.9 \%$.

Shorter LOHS as well as less hospitalization rates are known to indicate cost effectiveness. Many of the researchers that have reported shorter LOHS with either HS or NS have seen a difference of only few hours in between both the treatment groups which may not be clear indication of significant clinical outcomes. It is also important to note that natural history and pathophysiology of $A B$ could be different with the involvement of different viral agents. Many of the trials are with comparatively lower sample sizes so studies involving multiple sets of populations and larger sample size will further establish the benefits of studied drugs in the future to further clarify the findings of the present study.

\section{CONCLUSION}

Nebulized HS 3\% and NS $0.9 \%$ were not found to have any significant advantage over each other in terms of length of hospital stay among hospitalized children having acute bronchiolitis. Further studies involving larger sample size are needed to verify the results of this study. 


\section{ACKNOWLEDGEMENT}

The authors would like to thank Muhammad Aamir (Bahawalpur) for his valuable assistance in statistical analysis of this research.

Copyright@ 27 May, 2020.

\section{REFERENCES}

1. Fernandes RM, Andrade MG, Constant C, Malveiro D, Magalhaes M, Abreu D, et al. Acute viral bronchiolitis: Physician perspectives on definition and clinically important outcomes. Pediatric pulmonology. 2016; 51(7):724-32.

2. Erickson EN, Bhakta RT, Mendez MD. Pediatric bronchiolitis. [Updated 2020 Jan 30]. In: Stat Pearls [Internet]. Treasure Island (FL): Stat Pearls Publishing; 2020. Available from: https://www.ncbi.nlm.nih.gov/ books/NBK519506/.

3 .Silver AH, Nazif JM. Bronchiolitis. Pediatr Rev. 2019; 40(11):568-576.

4. American academy of pediatrics committee on infectious diseases; American academy of pediatrics bronchiolitis guidelines committee. Updated guidance for palivizumab prophylaxis among infants and young children at increased risk of hospitalization for respiratory syncytial virus infection. Pediatrics. 2014; 134(2):415-20.

5. Pelletier AJ, Mansbach JM, Camargo CA. Direct medical costs of bronchiolitis hospitalizations in the United States. Pediatrics 2006; 118; 2418-23.

6. Florin TA, Plint AC, Zorc JJ. Viral bronchiolitis. Lancet. 2017; 389(10065):211-224.

7. Hall CB. Respiratory syncytial virus and para influenza virus. N Engl J Med. 2001; 344:1917-1928.

8. DeVincenzo J, Pickles RJ. RSV and its propensity for causing bronchiolitis. J Pathol. 2015; 235(2): 266-276.

9. García CG, Bhore R, Soriano-Fallas A, Trost M, Chason $R$, Ramilo $O$, et al. Risk factors in children hospitalized with RSV bronchiolitis versus non-RSV bronchiolitis. Pediatrics. 2010; 126(6):e1453-60.

10. Ralston SL, Lieberthal AS, Meissner $\mathrm{HC}$ et al. Clinical practice guideline: The diagnosis, management, and prevention of bronchiolitis. Pediatrics. 2014; 134(5):e1474-e1502.

11. Ralston SL, Lieberthal AS, Meissner HC, Alverson BK, Baley JE, Gadomski AM, et al. Clinical practice guideline: The diagnosis, management, and prevention of bronchiolitis. Pediatrics. 2014; 134(5):e1474-1502.
12. Salman MK, Ashraf MS, Ahmad E. Comparison of $3.0 \%$ hypertonic saline versus $0.9 \%$ normal saline nebulization for acute bronchiolitis in children. $J$ Postgrad Med Inst 2018; 32(2): 128-31.

13. Bordley WC, Viswanathan M, King VJ, Sutton SF, Jackman AM, MSW; Sterling L, et al. Diagnosis and Testing in Bronchiolitis: A systematic review. Arch Pediatr Adolesc Med. 2004; 158(2):119-126.

14. Wang EE, Milner R, Allen U, Maj H. Bronchodilators for treatment of mild bronchiolitis: $A$ factorial randomised trial. Arch Dis Child. 1992; 67:289-93.

15. Gupta HV, Gupta VV, Kaur G, Baidwan AS, George PP, Shah JC et al. Effectiveness of $3 \%$ hypertonicsaline nebulization in acute bronchiolitis among Indian children: A quasi-experimental study. Perspect Clin Res 2016; 7:88-93.

16. Al-bahadily A-kJM, Al-Omrani AA-aM, Atiya AA. Hypertonic $3 \%$ saline in comparison with $0.9 \%$ (normal) saline in treatment of acute bronchiolitis. Int J Pediatr 2017; 5:4209-16.

17. Singh S, Kahlon PS, Neki N. A Comparative study to assess the efficacy of Nebulised $3 \%$ hypertonic saline and Nebulised I-adrenaline in treatment of acute bronchiolitis in children 1 month to 2 years. Int J Curr Res Med Sci 2017; 3:77-83.

18. Koker O, Ozdogan S, Kose G, Yildirmak ZY. Comparison of the efficacies of normal saline versus hypertonic saline in the management of acute bronchiolitis. Int $\mathrm{J}$ Contemp Pediatr 2016; 3:795-800.

19. Sarrell EM, Tal G, Witzling M, Someck E, Houri S, Cohen HA, et al. Nebulized $3 \%$ hypertonic saline solution treatment in ambulatory children with viral bronchiolitis decreases symptoms. Chest. 2002; 122(6):2015-20.

20. Zhang L, Mendoza-Sassi RA, Wainwright C, Klassen TP. Nebulized hypertonic saline solution for acute bronchiolitis in infants. Cochrane Database of Systematic Reviews 2008; 4: CD006458.

21. Chen YJ, Lee WL, Wang CM, Chou HH. Nebulized hypertonic saline treatment reduces both rate and duration of hospitalization for acute bronchiolitis in infants: An updated meta-analysis. Pediatr Neonatol 2014; 55:431-8.

22. Reisi M, Afkande N, Golmakani H, Khademian M. Normal Saline vs. Hypertonic saline nebulization for acute bronchiolitis: A randomized clinical trial. Int $\mathrm{J}$ Pediatr 2018; 6(11): 8507-16. 
23. Florin TA, Shaw KN, Kittick M, Yakscoe S, Zorc JJ. Nebulized hypertonic saline for bronchiolitis in the emergency department: A randomized clinical trial. J Am Med Asso Pediatr 2014; 168:664-70.
24. Sharma BS1, Gupta MK, Rafik SP. Hypertonic (3\%) saline vs $0.93 \%$ saline nebulization for acute viral bronchiolitis: A randomized controlled trial. Indian Pediatr. 2013; 50(8):743-7.

\section{AUTHORSHIP AND CONTRIBUTION DECLARATION}

\begin{tabular}{|c|l|l|l|}
\hline Sr. \# & \multicolumn{1}{|c|}{ Author(s) Full Name } & \multicolumn{1}{c|}{ Contribution to the paper } & Author(s) Signature \\
\hline 1 & Maleeha Saleem & $\begin{array}{l}\text { Data collection, Data analysis, } \\
\text { Drafting. } \\
\text { Methodology, Literature Reveiw, } \\
\text { Discussion. } \\
\text { Study concept, Supervision, } \\
\text { Proof reading. }\end{array}$ \\
3 & Maria Saleem & Asim Khurshid &
\end{tabular}

